\title{
ANALISIS KEPUTUSAN PEMBELIAN KONSUMEN DITINJAU DARI KUALITAS PRODUK, LOKASI DAN PROMOSI TERHADAP BUSANA BATIK DI PUSAT GROSIR SOLO
}

\author{
Deviana Putri, Burhanudin, Ratna Damayanti \\ Fakultas Ekonomi Jurusan Manajemen Universitas Islam Batik Surakarta. \\ ss.sotososo@gmail.com
}

\begin{abstract}
This study aims to prove and know the quality of products, locations and promotions simultaneously or partially towards the decision to purchase batik clothing. This type of research is a quantitative descriptive study, the population of this study is that all consumers who have bought batik clothing in PGS are infinite in number and the sampling method uses purposive sampling technique. The sample used was 100 respondents. The analytical method used is the method of multiple linear regression analysis. The method of data collection is by distributing questionnaires or questionnaires. The results showed that the $F$ test of product quality, location and promotion had a simultaneous and significant effect on purchasing decisions on batik clothing products at PGS, while the results of the t test showed that product quality had a positive and significant effect on purchasing decisions on batik clothing products at PGS, locations not influential and not significant towards purchasing decisions, promotion of influential products has a positive and significant effect on purchasing decisions on batik clothing products at PGS. The results of the coefficient of determination show that the independent variable $(X)$ product quality, location and promotion has an influence of $35.4 \%$ on the dependent variable $(Y)$ purchasing decisions on batik clothing products at PGS. The most influential variable is product quality.
\end{abstract}

Keywords: purchasing decisions, product quality, location, promotion

\section{PENDAHULUAN}

Peningkatan kesadaran masyarakat terhadap usaha melestarikan peninggalan leluhur yaitu batik, memunculkan minat masyarakat terhadap produk batik khususnya pada bidang fashion. Batik merupakan warisan budaya Indonesia, yang saat ini perkembangannya sangat pesat dalam dunia fashion. Perkembangan batik dalam dunia fashion medukung munculnya produsen batik yang baru dan meningkatkan kinerja produsen lama dalam memproduksi batik untuk memenuhi kebutuhan atau permintaan masyarakat terhadap batik sekarang ini (Agnes et al, 2014).

Dalam memilih batik konsumen memiliki beberapa kriteria yang termasuk diantaranya yaitu kualitas produk, kualitas produk menjadi salah satu faktor yang menjadi pertimbangan konsumen sebelum memutuskan untuk membeli suatu produk. Kualitas suatu produk ditentukan oleh manfaat dan fungsinya termasuk daya tahan, kenyamanan dan wujud luar seperti bentuk, warna, kemasan, dan lainnya (Weenas, 2013) Produk busana batik yang ada di PGS memiliki kualitas produk yang baik. Kualitas produk menjadi suatu pertimbangan paling utama, karena kualitas produk adalah tujuan bagi konsumen untuk memenuhi kebutuhannya (Rofiq dan Hufrom, 2017).

Kemudian faktor yang lain yaitu lokasi, lokasi mencakup letak toko atau tempat jual beli yang terletak di daerah strategis, karena saat ini konsumen tentunya sangat bijak dalam memilih 
lokasi tujuan pembelian mereka, karena mereka percaya lokasi yang bagus akan memberikan efek yang bagus pula dalam penjualannya (Senggetang, Mandey dan Moniharapon, 2019). PGS terletak pada lokasi yang strategis dengan banyak kemudahan akses menuju lokasi PGS.

Promosi, promosi uga termasuk faktor yang mempengaruhi seseorang dalam melakukan keputusan pembelian dalam kegiatan promosi biasanaya menonjolkan keistimewaan produk batik dan membujuk konsumen untuk membeli dengan memberikan potongan langsung ataupun hadiah langsung pada saat pembelian dapat menarik konsumen untuk membeli produk tersebut (Weenas, 2013). PGS menawarkan promosi harga lebih murah bila melakukan pembelian produk batik dalam jumlah yang banyak, PGS juga sering melakukan event-event dalam rangka menarik minat konsumen agar tertarik untuk melakukan pembelian produk di PGS.

Dari faktor-faktor yang ada diatas merupakan beberapa faktor yang mempengaruhi konsumen dalam melakukan keputusan pembelian. Keputusan pebelian ini juga menjadi salah satu faktor penting dalam menentukan eksistensi suatu produk. Suatu produk dapat terus eksis jika keputusan pembelian produk dari suatu pasar mendapatkan respon yang positif dari pasar itu sendiri (Abadi, Suddin dan Widajanti, 2018). Dari faktor-faktor yang ada diatas perumusan masalah yang ada dalam penelitian ini sebagai berikut: 1. Apakah terdapat pengaruh secara simultan Kualitas Produk, Lokasi dan Promosi Terhadap Keputusan Pembelian Busana Batik di PGS? 2. Apakah terdapat pengaruh Kualitas Produk Terhadap Keputusan Pembelian Busana Batik di PGS? 3. Apakah terdapat pengaruh Lokasi Terhadap Keputusan Pembelian Busana Batik di PGS? 4. Apakah terdapat pengaruh Promosi Terhadap Keputusan Pembelian Busana Batik di PGS?

\section{TINJAUAN PUSTAKA}

1. Keputusan Pembelian

Menurut Fandy Tjiptono (2015:21) keputusan pembelian merupakan sebuah proses dimana konsumen mengenal masalahnya, mencari informasi mengenai suatu produk atau merek tertentu dan mengevaluasi alternatif pemecahan masalahnya untuk kemudian mengarah pada pengambilan keputusan pembelian

2. Kualitas Produk

Menurut Kotler dan Amstrong (2010: 27) mengemukakan bahwa kualitas produk adalah kemampuan suatu produk untuk melaksanakan fungsinya yang meliputi kehandalan, daya tahan, kemudahan operasi, ketepatan dan perbaikan produk serta atribut yang bernilai lainnnya.

3. Lokasi

Menurut Fandy tjiptono dan Gregorius Chandra (2005), dalam melakukan pemilihan lokasi memerlukan pertimbangan yang cermat terhadap faktor-faktor berikut: lokasi yang mudah dijangkau, lalu lintasnya, lahan parkir yang luas, lingkungan yang mendukung, peraturan pemerintah yang mendukung, dan masih banyak lagi faktor lainnya.

4. Promosi

Menurut Kotler (2012:41) munyatakan bahwa promosi merupakan kegiatan perusahaan dalam menonjolkan keistimewaan-keistimewaan produknya kepada konsumen agar konsumn tertarik untuk membelinya. Diadakannya suatu promosi diharapkan dapat meningkatkan minat konsumen.

\section{METODE PENELITIAN}

Jenis penelitian ini merupakan penelitian deskriptif kuantitatif, populasi penelitian ini yaitu seluruh konsumen yang pernah melakukan pembelian busana batik di PGS dan sudah 
berumur lebih dari 17 tahun dan tehnik pengambilan sample menggunakan tehnik puposive sampling . penelitian ini mengambil sample sebesar 100 responden. Metode analisis yang digunakan adalah metode analisis regresi linear berganda. Metode pengumpulan data yaitu dengan menyebarkan lembar kuesioner atau angket.

\section{ANALISIS DATA DAN PEMBAHASAN}

\section{Analisis Data}

a. Uji Asumsi Klasik

Berdasarkan hasil pengujian menunjukkan nilai kolmogorov-smirnov sebesar 1,318 dan asymp.sig

Sebesar 0,062 hal ini menunjukan bahwa data penelitian ini normal.

b. Uji Multikolinearitas

Uji Multikolinearitas merupakan alat uji untuk menguji korelasi antar variabel bebas (Priyatno 2011: 195). Apabilaaniloai tolerance $>10$ dan $\mathrm{VIF}<10$, maka dapat disimpulkan bahwa tidak ada gejala multikolinearitas di model regresi. Berikut ini hasil ui mulikolinearitas pada tabel berikut:

Tabel Hasil Uji Multikolinearitas

\begin{tabular}{|cccccc|}
\hline Keterangan & Tolerance & Std & VIF & Std & Kesimpulan \\
\hline Kualitas & 0,850 & $>0,10$ & 1,176 & $<10$ & $\begin{array}{c}\text { Tidak ada } \\
\text { multikolinearitas }\end{array}$ \\
produk & & & & & Tidak ada \\
\hline lokasi & 0,841 & $>0,10$ & 1,389 & $<10$ & multikolinearitas \\
& & & & & Tidak ada \\
\hline Promosi & 0,986 & $>0,10$ & 1,014 & $<10$ & Multikolinearitas \\
\hline
\end{tabular}

Dari tabel diatas dari semua variabel nilai tolerancenya $>10$ dan nilai VIF $<10$ maka dapat disimpulkan bahwa seluruh variabel tidak terdapat penyimpangan atau tidak terjai multikolinearitas.

c. Uji Heterokedastisitas

Uji heterokedastisitas dengan menggunakan uji gletser yaitu dengan car meregres nilai residual terhadap variabel independen. Apabila $P_{\text {value }}<0,05$ maka tidak terjadi heterokedatisitas, selanjutnya jika $P_{\text {value }}>0,05$ maka terjadi heterokedatisitas. Dibawah ini hasil uji Heteokedastisitas:

\section{Hasil Uji Heterokedastisitas}

Variabel P-Value Batas Keterangan

(Sig)

$\begin{array}{ll}\text { Kualitas Produk } & 0,974\end{array} \geq 0,05 \quad$ Tidak terjadi heteroskedastisitas




\begin{tabular}{llll} 
Dari & 0,930 & $\geq 0,05$ & Tidak terjadi heteroskedastisitas \\
& 0,839 & $\geq 0,05$ & Tidak terjadi heteroskedastisitas \\
\hline
\end{tabular}

diatas dapat disimpulkan bahwa probabilitas value $X_{1}, X_{2}, X_{3}>0,05$ yaitu data berasal dari varian sama yang berarti tidak terjadi heterokedastisitas dan heterokedastisitas dapat diterima.

A. Analisis Data dan Hipotesis

1) Analisis Regresi Linear Berganda

Berikut ini tabel uji regresi linear berganda:

Tabel 3. Hasil Uji Regresi Linear Berganda

\begin{tabular}{lcrcc}
\hline \multicolumn{1}{c}{ Variabel } & B & t hitung & Sig t & Keterangan \\
\cline { 2 - 4 } Constant & 3,632 & 1,474 & & \\
Kualiatas Produk & 0,451 & 4,516 & 0,000 & Signifikan \\
Lokasi & 0,070 & 0,632 & 0,527 & Tidak Signifikan \\
Promosi & 0,282 & 3,368 & 0,001 & Signifikan \\
\hline
\end{tabular}

maka dapat disusun analisis regresi sebagai berikut :

$\mathrm{Y}=3,632+0,451 \mathrm{X} 1+0,070 \mathrm{X} 2+0,282 \mathrm{X} 3$

Dari persamaan regresi tersebut dapat diinterpretasikan sebagai berikut:

a. Nilai konstanta sebesar 3,632 menunjukan bahwa jika semua variabel independen nilainya 1, maka keputusan pembelian akan meningkat sebesar 3,632.

b. Nilai koefisien b1 sebesar 0,451 berarti kualitas produk berpengaruh positif terhadap keputusan pembelian. Jika kualitas produk meningkat maka keputusan pembelian sebesar 0,451 .

c. Nilai koefisien b2 sebesar 0,070 berarti apabila lokasi mengalami tingkatan sebesar satu satuan, maka keputusan pembelian dapat menurun sebesar 0,070 dengan asumsi nilai variabel bebas lainnya tetap sama.

d. Nilai koefisien b3 sebesar 0,282 berarti promosi berpengaruh positif terhadap keputusan pembelian, jika promosi meningkat maka keputusan pembelian meningkat sebesar 0,282 .

2) Uji F

Uji $\mathrm{F}$ digunakan untuk mengetahui pengaruh variabel independen atau variabel bebas yaitu kualitas produk $\left(\mathrm{X}_{1}\right)$, Lokasi $\left(\mathrm{X}_{2}\right)$, dan Promosi $\left(\mathrm{X}_{3}\right)$ secara simultan terhadap variabel terikat atau variabel dependen yaitu keputusan pebelian (Y). Nilai $F_{\text {hitung }}>F_{\text {tabel }}(17,432>2,70)$ maka Ho ditolak, sehingga variabel kualitas produk, lokasi dan promosi berpengaruh secara simulta terhadap keputusan pembelian busana batik di PGS. 
3) Uji t

uji t menguji seberapa kuat pengaruh variabel bebas pada sebuah penelitian mampu menerangkan variabel terikat secara individual (Ghozali 2012: 98) berdasarkan tabel 3. dapat diketahui bahwa :

a. untuk variabel kualitas produk $\left(\mathrm{X}_{1}\right)$ diperoleh nilai $\mathrm{t}_{\text {hitung }}$ sebesar 4,516 sedangkan besar $t_{\text {tabel }}$ adalah 1,984 ( $t_{\text {hitung }}>t_{\text {tabel }}$ ) sehingga dapat disimpulkan bahwa Ho ditolak berarti ada pengaruh signifikan kualitas produk $\left(\mathrm{X}_{1}\right)$ terhadap keputusan pembelian.

b. statistik untuk variabel lokasi $\left(\mathrm{X}_{2}\right)$ diperoleh nilai $\mathrm{t}_{\text {hitung }}$ sebesar 0,635 sedangkan besar $\mathrm{t}_{\text {tabel }}$ adalah 1,984 ( $\left.\mathrm{t}_{\text {hitung }}<\mathrm{t}_{\text {tabel }}\right)$ dengan nilai sinigfikan sebesar 0,635 $>0,05$ sehingga dapat disimpulkan bahwa Ho diterima berarti lokasi tidak berpengaruh signifikan terhadap keputusan pembelian.

c. variabel promosi $\left(\mathrm{X}_{3}\right)$ diperoleh nilai $\mathrm{t}_{\text {hitung }}$ sebesar 3,368 sedangkan besar $\mathrm{t}_{\text {tabel }}$ adalah $1,984\left(t_{\text {hitung }}>t_{\text {tabel }}\right)$ sehingga dapat disimpulkan bahwa Ho ditolak berarti terdapat pengaruh signifikan promosi $\left(\mathrm{X}_{3}\right)$ terhadap keputusan pembelian. d.

4) Uji KoefisienDeterminasi $\left(\mathrm{R}^{2}\right)$

$\mathrm{R}^{2}$ ( $\mathrm{R}$ square) merupakan alat ukur yang bertujuan untuk mengetahui keterlibatan seberapa jauh variabel independen dan variabel dependen. Hasil perhitungan Adjusted R2 diperoleh sebesar 0,353. Hal ini berarti bahwa variabel kualitas produk $\left(\mathrm{X}_{1}\right)$, lokasi $\left(\mathrm{X}_{2}\right)$ dan promosi $\left(\mathrm{X}_{3}\right)$ memberikan sumbangan variabel independen terhadap variabel dependen. Sumbangan variabel independen sebesar 0,353 (35,3\%) sedangkan 0,647 (64,7\%) dipengaruhi oleh variabel-variabel lain seperti harga , kualitas pelayanan dan lain sebagainya.

\section{Pembahasan}

a. Pengaruh kualitas produk (X1) terhadap keputusan pembelian (Y) produk busana batik di PGS.

Hasil penelitian yang telah dilakukan menunjukan variabel kualitas produk (X1) diperoleh thitung 4,516 dengan nilai signifikan 0,000 dan koefisien regresi mempunyai nilai positif 0,594 , berarti bahwa variabel kualitas produk berpengaruh positif dan signifikan terhadap keputusan pembelian produk busana batik di PGS.

b. Pengaruh lokasi (X2) terhadap keputusan pembelian(Y) produk busana batik di PGS

Hasil penelitian yang telah dilakukan menunjukan variabel lokasi (X2) diperoleh thitung 0,635 dengan nilai signifikan 0,57>0,05, berarti bahwa variabel lokasi tidak berpengaruh secara signifikan terhadap keputusan pembelian ) pada produk busana batik di PGS. Hal ini dikarenakan konsumen tidak terlalu memikirkan lokasi pembelian suatu produk, saat konsumen memiliki keinginan maupun kebutuhan batik maka mereka akan mendatangi berbagaitempat untuk memenuhi kebutuhan maupun keinginannya.

c. Pengaruh promosi $\left(\mathrm{X}_{3}\right)$ terhadap keputusan pembelian $(\mathrm{Y})$ produk busana batik di PGS.

Hasil penelitian yang telah dilakukan menunjukan variabel promosi $\left(\mathrm{X}_{3}\right)$ diperoleh thitung 3,368 dengan nilai signifikan 0,000 dan koefisien regresi mempunyai nilai positif 0,306 , berarti bahwa variabel promosi berpengaruh positif terhadap keputusan pembelian pada produk busana batik di PGS.

d. Pengaruh Kualitas Produk, Lokasi dan Promosi (X) terhadap keputusan pembelian (Y) produk busana batik. 
Nilai $F_{\text {hitung }}>F_{\text {tabel }}(17,432>2,70)$ maka Ho ditolak, sehingga variabel kualitas produk, lokasi dan promosi berpengaruh secara simulta terhadap keputusan pembelian busana batik di PGS.

\section{5) KESIMPULAN}

1. Diketahui bahwa variable kualitas produk, lokasi dan promosi berpengaruh secara bersama-sama atau simultan terhadap keputusan pembelian pada produk busana batik di PGS.

2. Secara parsial kualitas produk berpengaruh positif dan signifikan terhadapa keputusan pembelian pada produk busana batik di PGS.

3. Secara parsial lokasi tidak berpengaruh dan tidak signifikan terhadap pembelian pada produk busana batik di PGS.

4. Secara parsial promosi berpengaruh positif dan signifikan terhadap keputusan pembelian pada produk busana batik di PGS.

\section{SARAN}

Saran yang dapat diberikan penulis sehubungan dengan hasil penelitian ini sebagai berikut :

a. Sebaiknya produsen batik yang ada di PGS tetap mempertahankan kualitas produk yang telah ada dan selalu berinovasi menciptakan produk-produk ataupun model baru dalam dunia fashion batik yang dapat menarik minat beli konsumen terhadap produk-produk busana batik yang ada di PGS.

b. Sebaiknya promosi dilakukan secara berkala dan dalam lingkup yang lebih luas agar setiap masyarakat mengetahui produk yang ada di PGS

\section{DAFTAR PUSTAKA}

Abadi Dwi, Suddin Alwi dan Widajanti Erni. 2018. Pengaruh Kualitas Produk, Harga, Promosi Terhadap Keputusan Pembelian Kosumen Toko Mas Semar Dengan Kepuasan Pelanggan Sebagai Variabel Moderasi. Jurnal Manajemen Sumber Daya Manusia. Vol. 12 No. 2018, 1 Juni: $108-124$.

Agnes, Lisbeth dan Jantje Sepang. 2014. Pengaruh Kualitas Produk, Harga, Promosi dan Lokasi Terhadap Keputusan Pembelian Konsumen di Bentenan Center sonder Minahasa.Vol.2 No.3 September 2014. Hal 1737-1749.

Ghozali, Imam.2012.Aplikasi Analisis Multivariate dengan Program IBM SPSS 20.Semarang:Badan Penerbit UNDIP.

Haryanto Jony dan Priyanto Sony. 2013. Recent Future Reaserch In Consumer Behavior A Better Understanding Of Batik As Indonesian Heritage. Vol.-IV, No-4, Oktober 2013. Hal 32.

Kotler, Philip \& Garry Armstrong. 2010. Prinsip-Prinsip Pemasaran, Jilid 1 dan 2 Edisi Kedua Belas. Jakarta : Erlangga

Kotler, Philip dan Gary Amstrong. 2012. Prinsip-prinsip Pemasaran. Edisi 13. Jilid 1. Jakarta: Erlangga. 
Priyatno, Dwi. 2011. Buku Saku SPSS. Analasis Statistik Dengan Microsoff Excel \& SPSS. Penerbit Andi. Yogyakarta.

Rofiq, Ainnur dan Hufrom Muhammad. 2017. e - Jurnal Riset Manajemen PRODI MANAJEMEN Fakultas Ekonomi Unisma.

Sanggetang Vania, Mandey L. Silvya dan Maniharapon Silcyijeova. 2019. Pengaruh Lokasi Promosi dan Presepsi Harga Terhadap Keputusan Pembelian Konsumen pada Perumahan Kawanua Emerald City Manado. Vol. 7 No.1 Januari 2019. Hal. 881-890.

Tjiptono, Fandy. 2015.Strategi Pemasaran.Edisi 4. Yogyakarta: ANDI.

Weenas R.S. Jackson. Kualitas 2013. Kualitas Produk, Harga, Promosi Dan Kualitas Pelayanan Pengaruhnya Terhadap Keputusan Pembelian Spring Bed Comforta. Jurnal EMBA. Vol.1 No.4 Desember 2013, Hal. 607-618. 